\title{
Techno-Economic and Environmental Analysis for Off-Grid Mobile Base Stations Electrification with Hybrid Power System in Tanzania
}

\author{
Edvin J. Kitindi \\ Solomon Mahlango College of Science and Education, Sokoine University of Agriculture, Morogoro Tanzania
}

\begin{abstract}
Base stations (BSs) are essential in cellular networks. Lack of access to reliable electricity in mobile communication systems is a major economic and environmental concern for service delivery in Tanzania. Mobile network operators (MNOs) use diesel generators (DG) to power their BSs which are costly and high greenhouse gases (GHG) emissions. In this paper, we investigate challenges hindering the use of renewable energy (RE) by MNOs. We provide a techno-economic analysis for using a hybrid power system (HPS) comprising of DG and RE. In technoeconomic analysis, we considered solar, wind, battery, and DG in different configurations. The systems were simulated in HOMER to get the optimized model suitable for the BS sites. Results show that the solar/DG/Battery and the solar/wind/DG/Battery provide optimal solution susceptible to satisfy the needs. Although HPS suffers from the high initial cost, the results are satisfactory. The analysis indicates a reduction of net present cost (NPC) by 54\%, cost of energy (COE) by more than $50 \%$, and the GHG emissions for about $88 \%$.
\end{abstract}

Keywords: Off-grid base station, Net present cost, Greenhouse gases emissions, Mobile communication systems, Hybrid Power System, and Renewable energy

\section{INTRODUCTION}

Mobile communication plays great roles in both social and economic development sectors such as agriculture, education, and mining. Over last decades, telecommunication networks have experienced a global growth, leading to an increasing number of mobile users, and smart devices for mobile internet access. With such growth, there are however, about $53 \%$ of the world population mainly from developing countries of Asia-Pacific and Africa being unconnected to the network services. These unconnected population lives in remote areas where there is lack of access or difficulties in accessing the basic infrastructures such as electricity and/or transport, which impede the realization of the essential benefits of the telecommunication services in those areas.

Electricity is a key component for mobile communication systems growth. The base station (BS) or base transceiver station (BTS) utilizes about $80 \%$ of the energy consumed in telecommunication systems. In developing countries the remote BSs are powered by conventional diesel generators due to the unavailability of power grid. For sustainable communication system, electricity is an essential resource in providing a high quality communication services. By 2013, there were approximately four million macro BS sites worldwide each of which consumes about 25MWh of electricity per annum.

In survey conducted by the rural energy agency (REA) on behalf of the ministry of energy in 2020, revealed that; by 2020 the electrification rate in Tanzania was $78.4 \%$ by population, out of which $24.5 \%$ of the rural household are connected to the electricity. The Most main infrastructures/services connected to electricity in Tanzania mainland includes health facilities, financial institution, and education institutions. The MNOs were not in the list of the mentioned infrastructure being connected hence MNOs has to find the alternative energy sources to the most remotely BSs. Currently, the government is committed to accelerating electrification to the country to at least $75 \%$ by 2035 . Due to the lack of power supply, the mobile BSs for the rural areas in Tanzania are mainly powered by conventional diesel generators which have low energy efficiency, high operation and maintenance cost. Consequently, they lead to unfriendly environmental effects caused by greenhouse gas (GHG) emissions . Furthermore, the price for the diesel is high and unstable, and the demand for energy by telecom infrastructure increases every day.

Due to its importance, the telecommunication sector experiences a high growth rate and was estimated that by 2020 the diesel consumption by the off-grid and bad-grid mobile towers will increase by 13-15\% . Over 150 million barrels of diesel were expected to be annually consumed, spending over US\$19 billion and producing about 45 million tons of carbon dioxide (CO2) per year which are far away higher than 5 million tons of 2014.

Power supply is a challenge for MNOs in Tanzania, more than 30\% of existing BSs are off-grid and powered by diesel generators . Even the grid connected BSs are subject to load shedding and frequently power outage. In practice diesel generator can either be a backup or primary power source for mobile sites. Diesel generator runs the BSs connected to the power grid for an average of 8 hours per day. But at critical time about $20 \%$ of the grid connected BSs are out of 


\section{International Journal of Advanced Research in Computer and Communication Engineering}

Vol. 10, Issue 4, April 2021

\section{DOI 10.17148/IJARCCE.2021.10408}

power making the diesel generator to run for more than 12 hours per day, these sites are termed as bad grid BSs . For the off-grid BSs, the installed diesel generator operates for more than 12 hours per day depending on the energy plan setup. In 2020 for example, Helios towers report that approximately 20\% (734 sites) of their towers in the country are off-grid, and powered by diesel generator full time. In the site where a storage plan is installed the diesel generator operates for less hours than the one without battery storage.

With the aforementioned reasons, MNOs and researchers are looking for better ways of reducing cost and greenhouse gases emissions without compromising the quality of mobile services. This can be done in several ways such as minimizing the energy consumptions of BTS, implementing an intelligent monitoring for energy consumptions, and generating energy from green sources for off-grid BTSs sites. The MNOs and tower companies are very motivated towards the CAPEX model for green deployments, through investing in and owning energy infrastructures with other partners for operations and equipment maintenance. The OPEX model, based on outsourcing the production of energy and through MNOs paying for electricity based on consumption, can be done by other companies investing green energy supply.

Tanzania is situated in a potential solar belt region, it receives a high level of solar energy ranging from 2,800 to 3,500 hours of sunshine in a year. Also the country has a potential average wind speed of $5 \mathrm{~m} / \mathrm{s}$ at $10 \mathrm{M}$ altitude . However, these renewable energy sources contribute less than $4 \%$ to the nation electricity grid. The penetration of the solar energy is very low in African countries including Tanzania. Some factors that hinder the solar photovoltaic (PV) deployment in Africa include poverty, lack of awareness, lack of access to technical support services and financial means . About $65-70 \%$ of the mobile base stations in Tanzania are off-grid and bad-grid, they are powered by costly and environmentally unfriendly conventional diesel generators .

It is evident from the literature review that hybrid renewable energy systems are more cost effective and reliable source of energy than conventional grids or diesel generator system. The main focus of the renewable energy in Tanzania is on domestic use in rural areas, neglecting the electricity requirement for other sectors such as agricultural and telecommunication infrastructure. In other words, the main use of the renewable energy sources like solar is for basic household consumption such as lighting, charging mobile phones and may be powering the TV or radio set. To the best of the author's knowledge, there is no comprehensive studies on the HOMER-based techno-economic analysis for hybrid renewable energy systems in Tanzania that have been conducted. Being a developing country, Tanzania is economically dependent on agricultural sector which employs more than $80 \%$ of Tanzanian population. It has been revealed that the growth of the mobile network coverage improves the agriculture productivity due to the easy information acquiring and disseminations. The lack or insufficiency of electricity has significantly affected not only the communication and agricultural sectors but also the living conditions of the rural population. Therefore, the main aim of this study is to investigate the challenges that the MNOs face for using RE sources, and provide a techno-economic analysis to obtain an optimized, most feasible, and environmental friendly solution for the electrification of the remote base stations for MNOs in Tanzania where power grid is not available. Load, wind speed and solar radiation data were used for a techno-economic analysis in HOMER simulations tool.

The paper is organized as follows: Section II provides some related research, while Section III presents the methodology of the study. Section IV gives the survey results and analysis. Site location analysis is presented in Section V, whereas, section VI provides the hybrid power system and techno-economic analysis for the HPSs. Simulation results and discussion are presented in Section VII while recommendations and conclusion are given in Section VIII.

\section{RELATED WORKS}

For the last few years, the interest for HPSs which can provide electrification in various sectors has increased. The HPSs involve the green renewable and non-renewable energy sources. This can be practiced in many other sectors such as agriculture, and telecommunication sectors. For example, some MNOs have gone far by replacing the diesel power system with HPS, in last few years Orange group replaced about 1000 diesel system in their sites with HPS. HPS has been proven that during daytime hours, solar photovoltaic (Solar-PV) technology provides cheaper electrical energy compared to that generated by the conventional diesel generator. In addition, many studies have shown that by replacing the diesel power system with HPS, the carbon dioxide (CO2) emissions can be reduced up to 90\% . Another important factor that has been revealed is the reduction of the payback time for the HPS, which varies from 2-5 years depending on the project .

Extensive research studies on hybrid power systems for rural populations have been recently conducted in many countries such as India, South Africa, Nigeria, Turkey and Australia. Most of these studies involve stand-alone generators being integrated with renewable energy sources such as solar power and wind. The combination of renewable energy sources, especially the solar PV and wind turbines, with diesel generators can significantly reduce diesel fuel consumption, operational and maintenance cost. Additionally, there will be a potential reduction on GHG emissions to the environment.

The recent advancement in technology has led to rapid decline of solar PV cost, hence increasing sales which has supported large scale low cost manufacture of PV panels. Many advanced technological research studies demonstrated 


\section{International Journal of Advanced Research in Computer and Communication Engineering}

Vol. 10, Issue 4, April 2021

\section{DOI 10.17148/IJARCCE.2021.10408}

the production of more cost-effective PV panels. Solar PV is a very promising energy source, environmentally friendly and provides economic competitiveness. When solar-PV is deployed, it requires lowest maintenance and can easily be expanded to meet growing energy needs. Although the power output of PV cannot work alone due to its variation in nature, its contributions are appreciated as it can be available on average of about 8 to 10 hours in a day. In addition, the Solar PV alone cannot provide a continuous supply for all of the customer load demand for a 24-hour basis. Moreover, PV generation is at a maximum during the day time. Therefore, in planning and designing of the power sources for BSs, it is necessary to integrate solar PV, wind turbines into a grid or off-grid system with diesel generators and/or energy storage systems. PV-diesel power systems with energy storage can provide a reliable and efficient source of electrical power for rural or remote telecommunication sites .

The main challenge with renewable energy sources such as PV power is the initial capital cost, which is still high in comparison to that of diesel generator in spite of its high operating and maintenance costs, mainly resulting from the high diesel fuel delivery cost. Shaahid and El-Amin stressed that wind/PV/diesel hybrid system together with battery backup provide the most suitable energy configuration for all the telecom sites. Saheb-Koussa et al , designed a solar/diesel/battery hybrid power system for typical rural domestic use and the system met the required domestic load demand with an optimal performance. HPS developed to serve rural South African communities has shown to be a better choice financially, technically and environmentally . A wind-PV-diesel HPS was developed for a village in Saudi Arabia, provided about 35\% electrical supply (Commonly known as 35\% renewable energy penetration). An analysis of a solar-biomass HPS to power the agriculture irrigation system and residential in rural Pakistan is given in . The increase of solar PV capacity deployment has reduced the number of diesel generator operating hours.

Despite these wide potentials of renewable energy system, in Tanzania solar and wind energy contributes about $4 \%$ of electricity mainly for basic domestic uses. The deployment of green power solutions for the MNOs sites has not been given a priority and diesel generator is still the major source of power for the remotely situated BSs. This hinders the sector growth from connecting the rural areas, resulting into high cost for the mobile services in the country. Therefore, investigative studies of the challenges and potential of these energy sources in powering the communication network infrastructures in Tanzania are highly needed.

\section{METHODOLOGY}

This study aimed at exploring the challenges for renewable energy in powering the BTSs and its techno-economic potentials in Tanzania. A mixed approach (quantitative and qualitative) focussing on MNOs in Tanzania was employed.

\section{A. Research Design}

A survey design approach was employed in this study in investigating the challenges and the main source of the power for MNOs' infrastructure. A questionnaire was designed and distributed to the telecom engineers working with MNOs in Tanzania. Thirty five (35) experts involved in this study, working with different MNOs in different occupations. An average of two respondents from each MNOs participated in the survey. The questionnaire consisted of two parts. Section A designed to elicit demographic information of the respondents such as MNO working for, job title and experience in the field. Section B designed to gather information on the levels of applying renewable energy in powering the BTSs and its challenges. In section B we asked the respondents both open and closed questions in which open ended questions aimed at getting the respondents' opinions while the closed ended questions gave the respondents several items/statements to choose whatever applies to their cases.

\section{B. Data Collection Methods}

In this study both primary and secondary data were collected. Primary data were collected through questionnaires, person/telephonic interviews and researcher's observation. The stakeholders to whom the data were collected were the telecom engineers who work or being contracted by the MNOs in Tanzania.

Secondary data were collected from relevant documents about the renewable energy and its application in Tanzania. The data for the cost of some equipment such as diesel generator, solar panel were obtained from different vendor's websites and the average of price for equipment was considered for the simulation when verifying the potential of the renewable energy in the study area. At least three prices from different vendors' web pages were collected for each device and its average cost was used in HOMER for the data analysis.

\section{Study Area}

The study was conducted in Tanzania. However the renewable energy data were collected from six stations in Singida region, the central Tanzania. The study covered the following area with North-east corner: $-4.8118,34.6976$, and South-west corner: $-5.4684,34.357$ coordinate as indicated on the map in Fig. 1. The area was chosen based on the documentations that the central Tanzania is the area with high potential of solar and wind energy. The radiation and wind data were collected from global weather data for soil and water assessment tool (SWAT) database . Fig. 2 shows the schematic flow of the research procedure being conducted. We did the assessment of the RE problems through 


\section{International Journal of Advanced Research in Computer and Communication Engineering}

Vol. 10, Issue 4, April 2021

\section{DOI 10.17148/IJARCCE.2021.10408}

survey, the results are presented and identified the location where the potential of the RE sources were verified. Load, Cost and the resources were then identified and used for the design and techno-economic analysis in HOMER software. Finally the optimized results are presented and discussed.

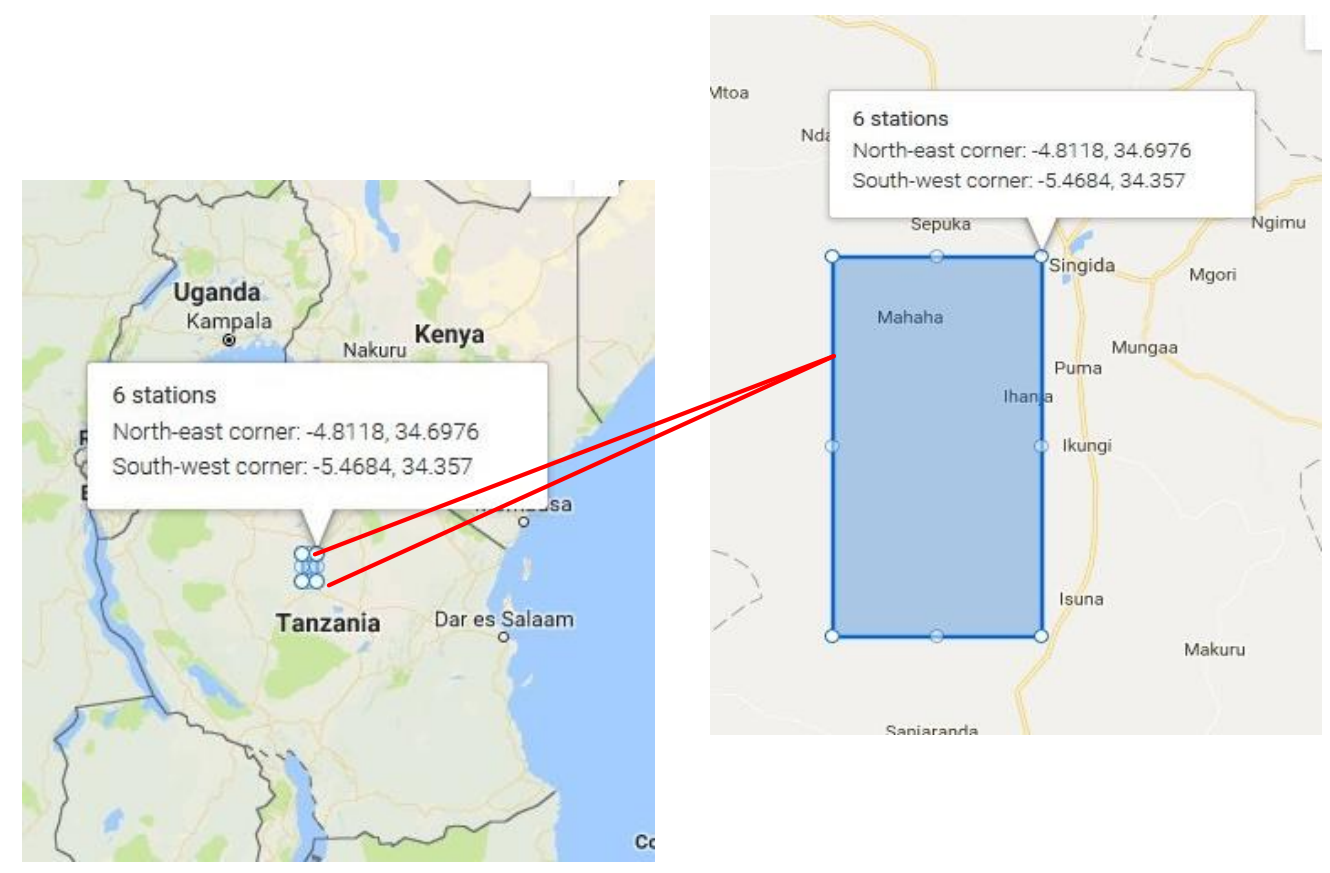

Fig. 1. Map details of the selected study area location

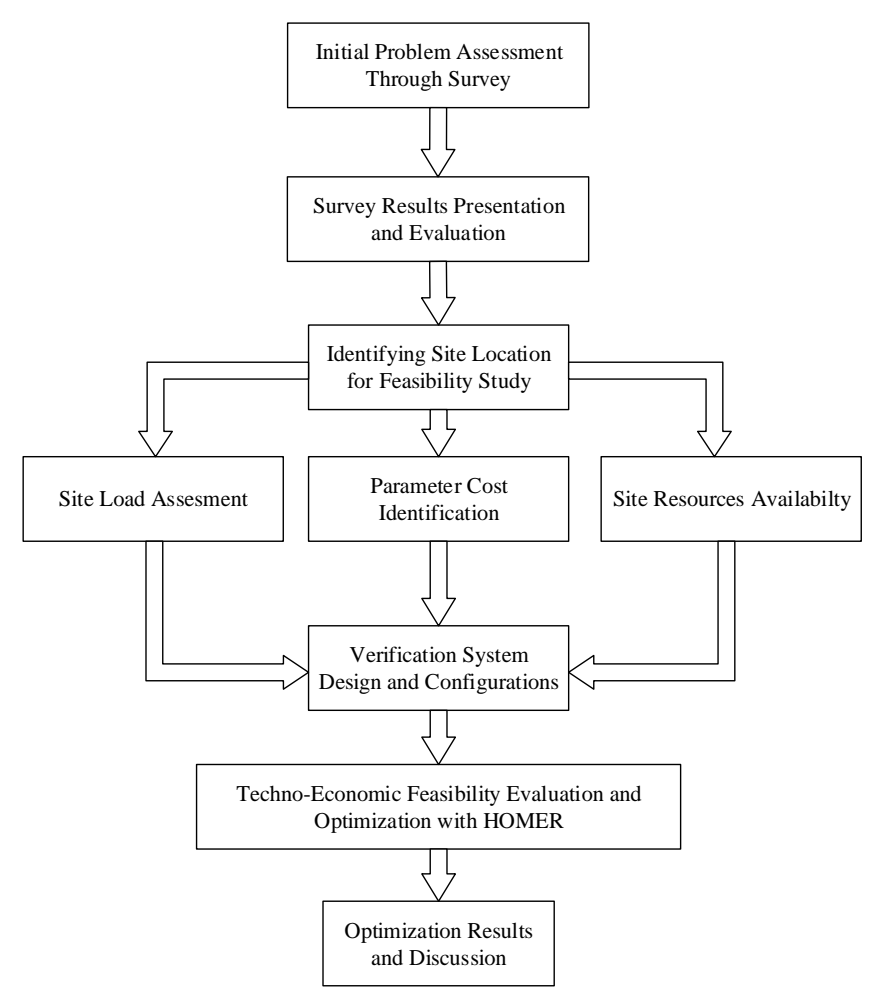

Fig. 2. Schematic Work flow

\section{SURVEY RESULTS PRESENTATION AND DISCUSSIONS}

The questionnaires were distributed to 35 people working or contracted by MNOs in technical aspects. 21 respondents filled out and sent back the questionnaire, giving a response rate of about 60 percent. The method used was purposive to explore the factors that affecting the use and growth of renewable energy sources in MNOs' infrastructures in 


\section{DOI 10.17148/IJARCCE.2021.10408}

Tanzania. The purposive sampling method means that the respondents have been selected on the basis of their expertise in MNO infrastructures. This method can lead to getting the right information from the right respondents. The returned had people from the following MNOs with their number of participants in brackets: Tigo Tanzania (3), Airtel Tanzania (2), Vodacom Tanzania (4), TTCL (3), and consultant companies (9).

Consultation companies who responded to the questionnaire are those which provide infrastructure as a service (IaaS) to the MNO in Tanzania, including the tower companies and the site supervisors. In this study, however, our focus is not to explore what expert from which company responded but to explore the challenges facing them for electrifying their remotely sites. Therefore, the response does not represent the status or opinion of the MNOs or consultant companies.

The first question in the questionnaire aimed at collecting some background information of the respondents. It was asking information about their employment and titles. This was required to ensure that the respondent qualify for providing the required information. Fig. 3 illustrates respondents' job titles distribution. The highest number of the respondents were the site supervisors $(33 \%)$ followed by project managers $(24 \%)$ while the least were the programmers $(10 \%)$.

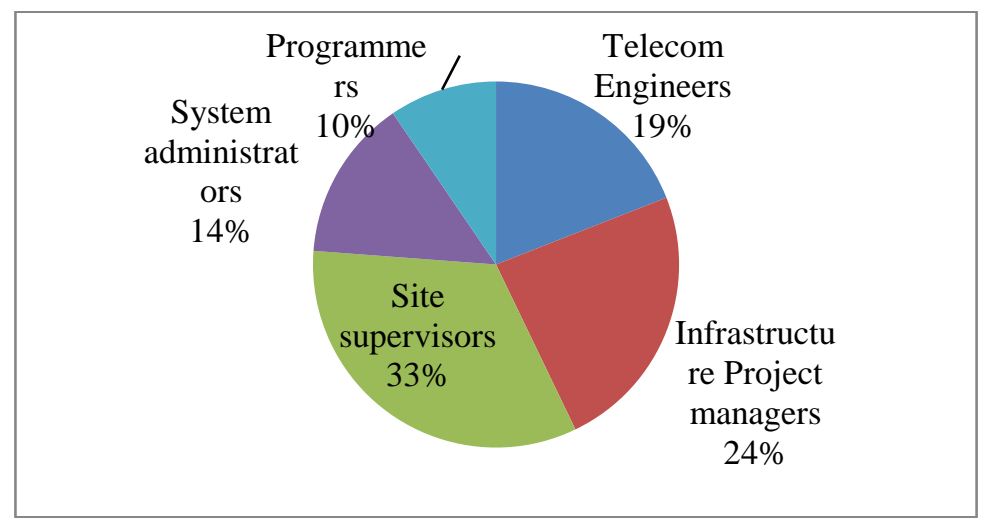

Fig. 3 Distribution of the respondents Job Titles

A. General Sources of Electric Power for the Mobile Infrastructure

Twenty one (21) respondents responded to the questions related to the main source of the power for network infrastructures. As shown in Fig. 4, the main power supply is from the grid and the Diesel generator. However, some MNOs use solar power to some extent. It can be observed that the renewable energy is not considered as the main source of power for network infrastructure in Tanzania.

The respondents provided various reasons for their choices of the sources of energy. Such reasons include the ease of availability of the facilities. They stressed that power grid is mostly used in urban but diesel generator is installed as backup. Solar system is used by some MNOs but not to the high extents. In conclusion, the MNOs do not use much of the available renewable energy to power their infrastructure. 95\% uses grid power and diesel generator as their main sources of the power. In Tanzania these sources face various challenges such as high operational cost, unreliable and environment unfriendly.

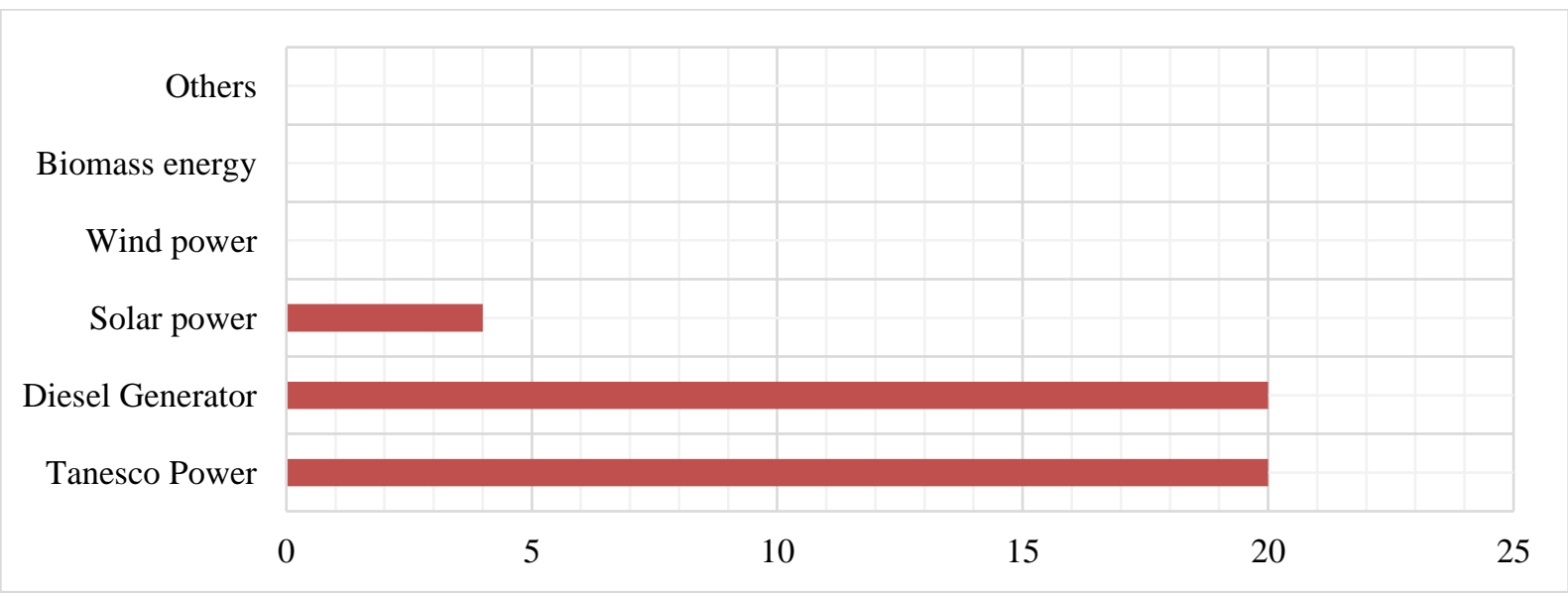

Fig. 4 The general power sources for network Infrastructures in Tanzania

B. Main Sources of Energy for Remotely Sites 


\section{DOI 10.17148/IJARCCE.2021.10408}

The researchers were interested to know the main sources of the power in the remote area sites. The questions were open in order to give respondent more room for explanation. Based on the responses as shown in Fig. 5, the grid is the main source of the power in any connected area. However, the respondents stressed that the grid power is not reliable due to various reasons. Therefore, a diesel generator becomes their first choice for powering the remotely sites. About $62 \%$ of the respondents indicated that, diesel generators are used to power the remote sites in Tanzania.

The solar systems have been used by some MNOs especially where there is a difficulty in accessing the site. They detailed that some remote sites are very potential and BSs required to be deployed in a specific areas, they do deploy solar system in such environment to reduce the frequently fuel refilling.

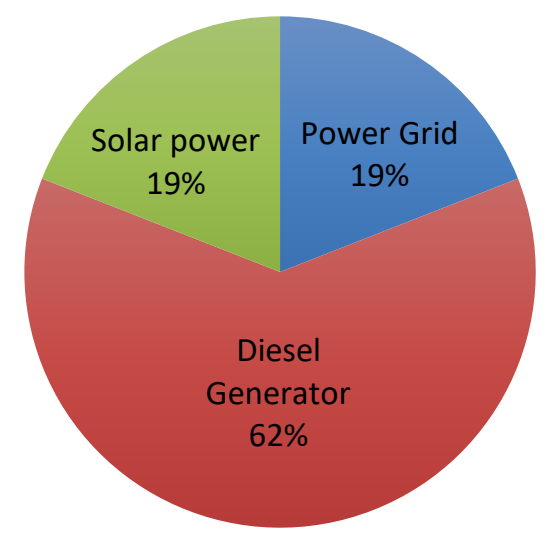

Fig. 5 Specific energy sources for network remote sites in Tanzania

C. Challenges of RE for Remote Sites Electrification

The researcher wanted to know the challenges that the MNOs face when using or want to use the RE for powering their sites especially for the countryside sites. All returned questionnaire responded to the related questions. The respondents were given options to choose as much as it applies and also given space to give other challenges which were not in the list. The results are as illustrated in Table 1. High installation cost, unpredictable weather conditions, unskilled personnel and deficits of the RE equipment were the most challenges being identified. Some of the challenges are similar to those in .

The results show that some MNOs are not interested to invest in the RE to power their sites. Four respondents indicated this challenge. This might be the respondent's opinion after working with the MNOs. Theft of the RE accessories in the site was also mentioned by eight (8) respondents. This shows that some site are not well secured to protect the equipment or the setting of the equipment is not being well protected which allows intruders to enter and steal the accessories.

TABLE 1 RE CHALLENGES FOR MNOS IN TANZANIA FROM SURVEY RESPONSES.

\begin{tabular}{lcc}
\hline \hline Challenges & Responses & Percentages \\
\hline High installation cost & 20 & $95 \%$ \\
High running cost & 8 & $38 \%$ \\
Unpredictable weather conditions & 20 & $95 \%$ \\
Site theft & 8 & $38 \%$ \\
Lack of skilled personnel & 12 & $57 \%$ \\
Unavailability of renewable energy facilities & 16 & $76 \%$ \\
MNOs not interested on RE & 4 & $19 \%$ \\
\hline \hline
\end{tabular}

The questionnaire examines the respondents' awareness about the various issues in respect to renewable energy in Tanzania. All the elements in the questionnaire are linked to the main aim of this study. Identifying the main sources of the energy and investigating the challenges for using RE in powering MNOs' infrastructure. Among the challenges being listed unpredictable weather conditions has been mentioned by many respondents. This indicates that there is less potential of the RE especially the solar energy. With this we will verify the potential of the RE (solar and the wind energy) by simulation using HOMER pro software. The main target was to investigate the net present cost (NPC), cost of energy (COE), GHG emissions, power production and the RE rate. The next section will provide the site location analysis with the corresponding load, cost of parameters and the site resources availability. 


\section{SITE LOCATION ANALYSIS}

The study was conducted in areas as described in the methodology subsection 3.3. In this section we describes the load, parameter cost and availability of the RE resources. The solar radiation and wind data for the location were collected from global weather data for SWAT database .

\section{A. Load Assessment}

In our model we consider a load of $54 \mathrm{kWh} /$ day with a peak load of $6.68 \mathrm{kWh}$. Considering the daily peak load demand at the given remote site, the proposed hybrid powering system comprises a generator with rated power of $7.5 \mathrm{~kW}$. The load assumption is based on the phone interview with four (4) telecom engineers in the two biggest MNOs in Tanzania mainland where the daily load demand has been considered. Other simulation parameters are shown in Table 3 as obtained from different sources such as vendors and merchant websites.

B. Energy Resources Assessment

The renewable energy sources being considered in this study are wind and solar energy. The choice is based on the fact that Tanzania has potential resources for these types of the energy especially in central Tanzania . The average data for wind speed and solar radiations obtained for the study area are presented in Table 2.

TABLE 2: WIND SPEED AND SOLAR RADIATIONS

\begin{tabular}{lcc}
\hline \multicolumn{1}{c}{ Months } & Wind $(\mathbf{m} / \mathbf{s})$ & Solar $\left(\mathbf{k W h} / \mathbf{m}^{2}\right)$ \\
\hline January & 1.924485 & 5.854705 \\
February & 2.020683 & 6.88692 \\
March & 3.065668 & 6.261448 \\
April & 2.554799 & 5.812094 \\
May & 3.770507 & 6.158144 \\
June & 3.997665 & 6.672007 \\
July & 4.025911 & 6.940548 \\
August & 4.506906 & 7.316757 \\
September & 4.311687 & 7.055355 \\
October & 4.779124 & 7.610208 \\
November & 3.825454 & 6.319972 \\
December & 2.196702 & 5.752554 \\
\hline \hline
\end{tabular}

C. Cost of the parameters for RE analysis

This subsection provides the prices data for various parameters as required by the HOMER to provide the optimized results after simulation. HOMER needs to be provided by some inputs to process the analysis. These inputs include the equipment expenses, availability of energy sources, and technologies which then produce the results. In Table 3 , we provide the expenses data of various component used as inputs in HOMER.

TABLE 3 SIMULATION DATA AND STUDY ASSUMPTIONS FOR HPS.

\begin{tabular}{lll}
\hline \hline Components & Descriptions & Value/Information \\
\hline & Minimum load ratio $(\%)$ & 40 \\
& Capital Cost & $\$ 1400 / \mathrm{kW}$ \\
Diesel Generator & Replacement Cost & $\$ 1250 / \mathrm{kW}$ \\
& Operation \& Maintenance Cost & $\$ 0.5 / \mathrm{hour}$ \\
& Lifetime & 15000 hours \\
& Fuel price & $\$ 1.1 / \mathrm{L}$ \\
& & \\
Solar Photovoltaic & Capital Cost & $\$ 2500 / \mathrm{kW}$ \\
& Replacement Cost & $\$ 2000 / \mathrm{kW}$
\end{tabular}




\begin{tabular}{lll} 
& $\begin{array}{l}\text { Operation \& Maintenance Cost } \\
\text { Lifetime }\end{array}$ & $\begin{array}{l}\$ 50 / \mathrm{year} \\
20 \text { years }\end{array}$ \\
& & \\
& Capital Cost & $\$ 300 / \mathrm{kW}$ \\
Bidirectional Converter & Replacement Cost & $\$ 300 / \mathrm{kW}$ \\
& Operation \& Maintenance Cost & $\$ 5 / \mathrm{year}$ \\
& Lifetime & 15 years \\
& & \\
Cind Turbines & Replacement Cost & $\$ 6100 / \mathrm{kW}$ \\
& Operation \& Maintenance Cost & $\$ 3500 / \mathrm{kW}$ \\
& Lifetime & 20 years \\
& & \\
& Capital Cost & $\$ 220 / \mathrm{kW}$ \\
Battery & Replacement Cost & $\$ 220 / \mathrm{kW}$ \\
& Operation \& Maintenance Cost & $\$ 10 / \mathrm{year}$ \\
& Lifetime & Depend on usage \\
\hline \hline
\end{tabular}

\section{VI.SYSTEM SET-UP FOR TECHNO-ECONOMIC ANALYSIS AND EVALUATIONS}

The setup comprises solar, wind power, diesel generator, and the storage battery for powering the remote off-grid BTS in Tanzania. Fig. 7 illustrates the general setup of hybrid micro-grid systems configuration. It consists of four parts, i.e., BTS load, power generation, controller, and the energy storage. In this system we consider solar and wind being the primary sources of the energy. When the generated electrical power exceeds the load demand, the excess energy is stored in the battery banks. The diesel generator supply power to BTS when the primary sources fail to supply enough energy to meet the BTS demand; and the battery riches its threshold discharge level. In our system we assume that the BTS provides an AC load hence we include an inverter in the regulation and conversion controller.

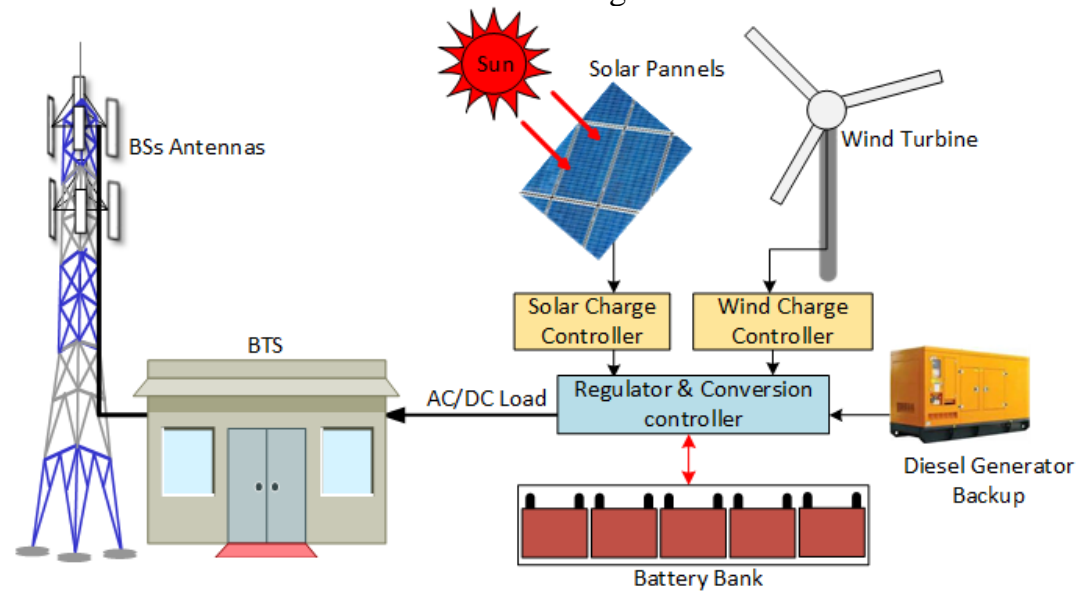

Fig. 7. General setup of hybrid power system for remote off-grid BTS (denoted as S3)

For the feasibility analysis purposes we consider four configurations as shown in Table 4 . We consider these settings to have more options for comparisons after we simulate the systems in the HOMER pro software. In this system, we investigate the economic and environmental impacts of integrating the power system for remote off-grid BTS. During the discussion we use the symbols to represent the corresponding settings cases. In each of the case we investigate the amount of GHG emissions, net present cost (NPC), cost of Energy (COE), electrical energy produced, RE rate and the fuel consumption per year.

\section{A. HPS Architecture}

TABLE 4. CONFIGURATIONS SETTING FOR EVALUATION

\begin{tabular}{lc}
\hline \hline Configuration settings & Symbol \\
\hline Diesel Generator & $\mathrm{S} 0$ \\
Diesel Generator/Wind/Battery & $\mathrm{S} 1$ \\
Diesel Generator/Solar/Battery & $\mathrm{S} 2$ \\
Diesel Generator/Solar/Wind/Battery & $\mathrm{S} 3$ \\
\hline \hline
\end{tabular}




\section{DOI 10.17148/IJARCCE.2021.10408}

The main aim of this subsection in this study is to develop a hybrid power system for remote BTS sites. We use the S3 configuration with an addition of bidirectional inverter as the general system. The system architecture is given in Fig. 8 as obtained from the HOMER simulation software.

HOMER software models a power system physical behaviour, and is used to evaluate different design possibilities both for off-grid and grid-connected power systems. It includes the remote, stand-alone and distributed power generation applications. In this research the main inputs to HOMER involve the data for diesel generator, solar panels, base station load demand, cost for all the system components with their corresponding specifications, and other relevant information used for model optimization. The main reasons for using HOMER system are: It simulates thousands of system configurations, provides the optimized configurations, and generates multiple results to produce sensitivity analysis for most of the inputs.

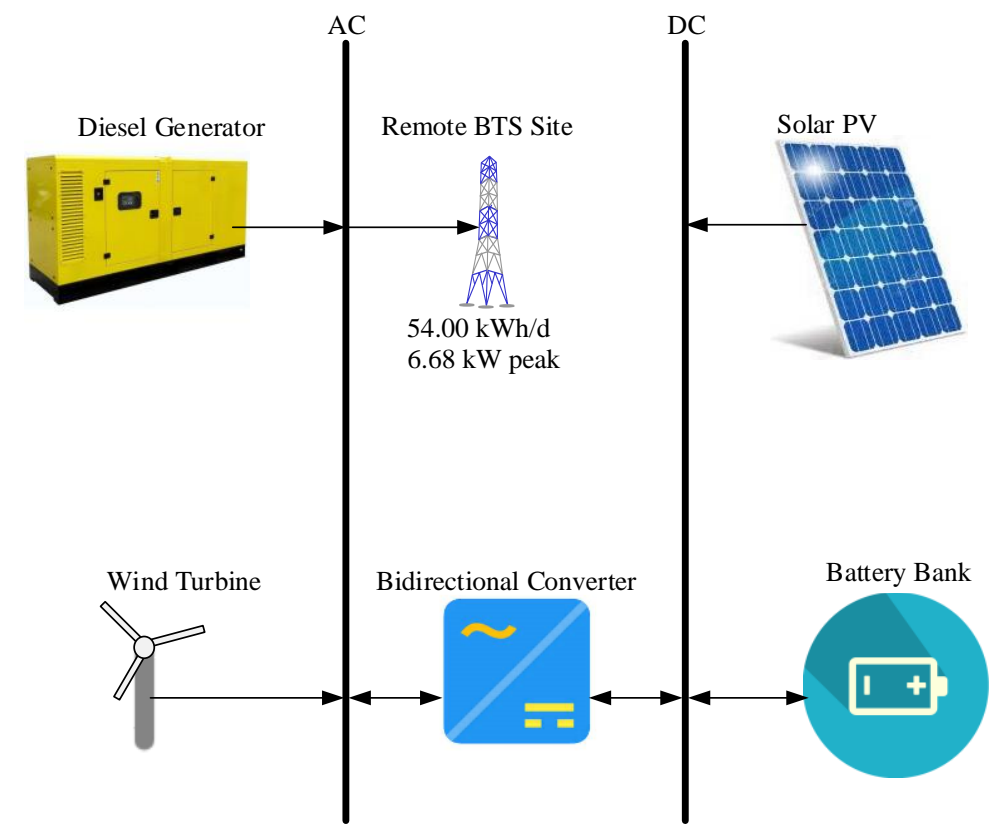

Fig. 8. Architectural System model of S3

HOMER gives useful analysis which supports the decision making for a developed system model. The results from HOMER help in making appropriate recommendations for developing hybrid power systems. The variables considered for simulations evaluations are solar irradiance, wind speed, diesel generator and fuel prices. The HOMER gives NPC, COE, GHG emissions and renewable fraction (RF) as outputs. The simulations are undertaken for every possible system configuration in a year. The simulations were carried out in computer system with an Intel Core i5 CPU, 4.0 GB of RAM powered by Windows 7 professional operating system.

\section{B. Evaluation metrics}

Various performance metrics are considered in this work, including NPC, COE, GHG emissions, electrical production, and RF. A comparison analysis for different system configurations in respect to these metrics is provided.

NPC of the system is the present value of all the cost incurred for a lifetime minus the revenue that it earns over the life time. Costs include capital costs, replacement costs, operational and maintenance costs, fuel costs, and gaseous emissions penalties if available. The HOMER software evaluates NPC as follows:

$$
N P C(\$)=\frac{\left[(1+i)^{N}-1\right] \times C_{T}}{i(1+i)^{N}}
$$

Where $\mathrm{N}$ is the number of years, $\mathrm{i}$ is the annual real interest rate (\%), and $C_{T}$ is the total annualized cost. The COE is the average cost per kWh of the electricity which is calculated through dividing the annualized cost of electricity generation to the total electric energy utilized i.e.

$$
C O E=\frac{C_{T}}{E_{c}}
$$




\section{DOI 10.17148/IJARCCE.2021.10408}

Whereby Ec is the total electrical energy consumed. In hybrid power system the lower NPC and COE are preferable. HOMER calculates the RF by dividing the total annual energy generated from renewable power sources to the total annual energy production i.e.,

$$
R F=\frac{E_{r}}{E_{T}}
$$

Whereby Er is the total annual energy from renewable sources and ET is the total annual energy produced from all the sources. The higher the RF is the better the system output.

GHG emissions are the products from the burning fossil fuel. The carbon emission quantity (CEQ), for example, carbon dioxide is calculated as follows:

$$
C E Q=F F C \times \mathrm{CO}_{2} E F
$$

Whereby $F F C$ is a fossil fuel consumption and $\mathrm{CO}_{2} E F$ is the carbon dioxide emission factor.

\section{RESULTS ANALYSIS AND DISCUSSION}

The hybrid power model has been designed and simulated using HOMER software tools. We considered four configurations (S0, S1, S2 and S3) for the analysis and comparisons. The optimization results from the HOMER are illustrated in the Fig. 9. The simulation however provides several configurations and arranges them in ascending order of NPC. Our analysis is based on the GHG emission, system cost (NPC, replacement cost, COE, Operational \&

\begin{tabular}{|c|c|c|c|c|c|c|c|c|c|c|c|c|c|}
\hline \multicolumn{12}{|c|}{$\begin{array}{l}\text { Optimization Results } \\
\text { Left Double Click on a particular system to see its detailed Simulation Results. }\end{array}$} & \multicolumn{2}{|c|}{ - Categorized (1) Overal } \\
\hline \multicolumn{9}{|c|}{ Architecture } & \multicolumn{4}{|c|}{ Cost } & \multirow{2}{*}{$\begin{array}{c}\text { System } \\
\text { Ren Frac } \\
(\%)\end{array}$} \\
\hline$m$ & 个 & - & E⿰马? & ( & $\begin{array}{c}\text { Solar PV } \\
(\mathrm{kW})\end{array}$ & Turbine $\nabla$ & $\begin{array}{c}\text { Diesel Generator } \nabla \\
(\mathrm{kW})\end{array}$ & Battery Bank $\nabla$ & ${ }_{(\$)}^{\mathrm{COE}} \nabla$ & $\begin{array}{c}\mathrm{NPC} \\
(\$)\end{array}$ & $\begin{array}{l}\text { Operating cost } \nabla \\
(\$)\end{array}$ & $\begin{array}{c}\text { Initial capital } \nabla \\
\text { (\$) }\end{array}$ & \\
\hline$m$ & & E & 睡 & z & 9.82 & & 7.40 & 52 & $\$ 0.433$ & $\$ 110,417$ & $\$ 4,923$ & $\$ 46,776$ & 83 \\
\hline$m$ & 个 & E & 相 & z & 9.73 & 1 & 7.40 & 52 & $\$ 0.460$ & $\$ 117,240$ & $\$ 4,996$ & $\$ 52,649$ & 83 \\
\hline$m$ & & & 㑭 & z & 23.8 & & & 104 & $\$ 0.660$ & $\$ 168,133$ & $\$ 6,475$ & $\$ 84,422$ & 100 \\
\hline \multirow[t]{3}{*}{ 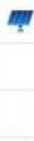 } & 个 & & 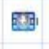 & z & 23.7 & 1 & & 104 & $\$ 0.688$ & $\$ 175,087$ & $\$ 6,557$ & $\$ 90,316$ & 100 \\
\hline & & E & 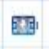 & 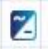 & & & 7.40 & 20 & $\$ 0.720$ & $\$ 183,548$ & $\$ 13,073$ & $\$ 14,542$ & 0.0 \\
\hline & 个 & $\vec{E}$ & 国 & $\boldsymbol{z}$ & & 1 & 7.40 & 20 & $\$ 0.745$ & $\$ 189,904$ & $\$ 13,094$ & $\$ 20,636$ & 0.0 \\
\hline 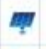 & & - & & $\tilde{z}$ & 11.6 & & 7.40 & & $\$ 0.819$ & $\$ 208,573$ & $\$ 13,055$ & $\$ 39,804$ & 3.1 \\
\hline \multirow[t]{3}{*}{ 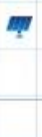 } & 个 & E & & $\approx$ & 12.5 & 1 & 7.40 & & $\$ 0.846$ & $\$ 215,545$ & $\$ 12,943$ & $\$ 48,224$ & 5.2 \\
\hline & & E & & & & & 7.40 & & $\$ 0.945$ & $\$ 240,663$ & $\$ 17,894$ & $\$ 9,339$ & 0.0 \\
\hline & 个 & $E$ & & & & 1 & 7.40 & & $\$ 0.972$ & $\$ 247,728$ & $\$ 17,969$ & $\$ 15,439$ & 0.0 \\
\hline
\end{tabular}
Maintenance Cost), amount of diesel used, excess electricity produced, and the RF.

Fig. 9 Optimization results depicted from HOMER

\section{A. GHG emissions}

GHG emissions are threat to the environment, and therefore system operators are to find better ways to keep them into small levels as they cause environmental pollution and the global warming. From the simulation results, the S3 shows that the amount of GHGs emissions are significantly reduced compared to the traditional system S0 for the remote base stations. GHGs emissions reduced for about $88 \%$ compared with the traditional S0. The results for the GHG emissions are presented in Table 5 with other system configurations being considered in this study. The tradition system produces $27,227 \mathrm{Kg} /$ year of carbon dioxide (CO2) while the proposed system emits just 3,122Kg/year of $\mathrm{CO} 2$. In summary the hybrid system is more environment and economical friendly to the MNOs in Tanzania.

TABLE 5. GHG EMISSIONS FOR DIFFERENT POWER SYSTEM CONFIGURATIONS

\begin{tabular}{cllcccc}
\hline \hline Architecture & $\begin{array}{l}\text { Carbon } \\
\text { Dioxide } \\
(\mathrm{Kg} / \mathrm{yr})\end{array}$ & $\begin{array}{l}\text { Carbon } \\
\text { Monoxide } \\
(\mathrm{Kg} / \mathrm{yr})\end{array}$ & $\begin{array}{l}\text { Unburned } \\
\text { Hydrocarbon } \\
(\mathrm{Kg} / \mathrm{yr})\end{array}$ & $\begin{array}{l}\text { Particulate } \\
\text { Matter }(\mathrm{Kg} / \mathrm{yr})\end{array}$ & $\begin{array}{l}\text { Sulphur } \\
\text { Dioxide } \\
(\mathrm{Kg} / \mathrm{yr})\end{array}$ & $\begin{array}{l}\text { Nitrogen } \\
\text { Oxide }(\mathrm{Kg} / \mathrm{yr})\end{array}$ \\
\hline S0 & 27227 & 172 & 7 & 1 & 67 & 161 \\
S1 & 19158 & 121 & 5 & 1 & 47 & 113 \\
S2 & 3123 & 20 & 1 & 0 & 8 & 18 \\
S3 & 3122 & 20 & 1 & 0 & 8 & 18 \\
\hline \hline
\end{tabular}


B. Cost system analysis

Table 6 provides a summary for economic comparison for different power system configurations. The S2 offers better economic solution towards the NPC, and COE. It reduced the NPC and COE from $\$ 240,663$ to $\$ 110,417$ and $0.945 \$ / \mathrm{kWh}$ to $0.433 \$ / \mathrm{kWh}$ respectively in comparison to S0 a traditional power system. However, the S3 configuration also gives a better economic solution. The main disadvantage observed from the simulation for the HPS is the initial capital cost. The initial capital is very high compared to the conventional system. But with advancement in technology, solar-PVs are becoming cheap which give advantages to the MNOs and the societies at large.

TABLE 6 COST SUMMARY FOR DIFFERENT POWER SYSTEM CONFIGURATIONS

\begin{tabular}{lllllll}
\hline \hline Architecture & $\begin{array}{l}\text { Capital } \\
\mathbf{( \$ )}\end{array}$ & $\begin{array}{l}\text { Replacement } \\
\mathbf{( \$ )}\end{array}$ & $\mathbf{O ~ \& ~ M ~ ( \$ ) ~}$ & Fuel Cost (\$) & NPC (\$) & $\begin{array}{l}\text { COE } \\
\mathbf{( \$ / k W h )}\end{array}$ \\
\hline S0 & 9,339 & 59,053 & 25,140 & 147,910 & 240,663 & 0.945 \\
S1 & 20,636 & 50,401 & 16,746 & 104,074 & 189,904 & 0.745 \\
S2 & 46,776 & 37,345 & 15,910 & 16,963 & 110,417 & 0.433 \\
S3 & 52,649 & 38,342 & 16,506 & 16,963 & 117,240 & 0.460 \\
\hline \hline
\end{tabular}

C. Electricity production

The electricity generated by the HPS is presented in Table 7. S2 and S3 produce more electricity from renewable energy sources than S0 and S1. Renewable energy fraction for S2 and S3 is about $83 \%$ indicating that the location has more potential of the RE for powering the remote network infrastructure. The electrical productions by S2 and S3 have been presented graphically as shown in Fig. 10 and 11.

TABLE 7 ELECTRICAL PRODUCTION FOR EACH COMPONENT IN A GIVEN SYSTEM CONFIGURATION

\begin{tabular}{clcccccc}
\hline \hline Architecture & $\begin{array}{l}\text { Diesel } \\
\text { generator } \\
(\mathbf{k W h} / \mathbf{y r})\end{array}$ & $\begin{array}{l}\text { Solar-PV } \\
(\mathbf{k W h} / \mathbf{y r})\end{array}$ & $\begin{array}{l}\text { Wind } \\
\text { Turb. } \\
\mathbf{( k W h / y r )}\end{array}$ & $\begin{array}{l}\text { Fuel Consumed } \\
(\mathbf{L} / \mathbf{y r})\end{array}$ & $\begin{array}{l}\text { Diesel } \\
\text { generator } \\
\text { hours } \\
(\mathbf{H r s} / \mathbf{y r})\end{array}$ & $\begin{array}{l}\text { Excess } \\
\mathbf{p o w e r} \\
(\mathbf{k W h} / \mathbf{y r})\end{array}$ & $\begin{array}{l}\text { RF } \\
(\%)\end{array}$ \\
\hline S0 & 27797 & 0 & 0 & 10401 & 8760 & 8087 & 0 \\
S1 & 21912 & 0 & 147 & 7319 & 4649 & 23 & 0 \\
S2 & 3380 & 21139 & 0 & 1193 & 881 & 1949 \\
S3 & 3375 & 20937 & 147 & 1193 & 884 & 1902 \\
\hline \hline
\end{tabular}

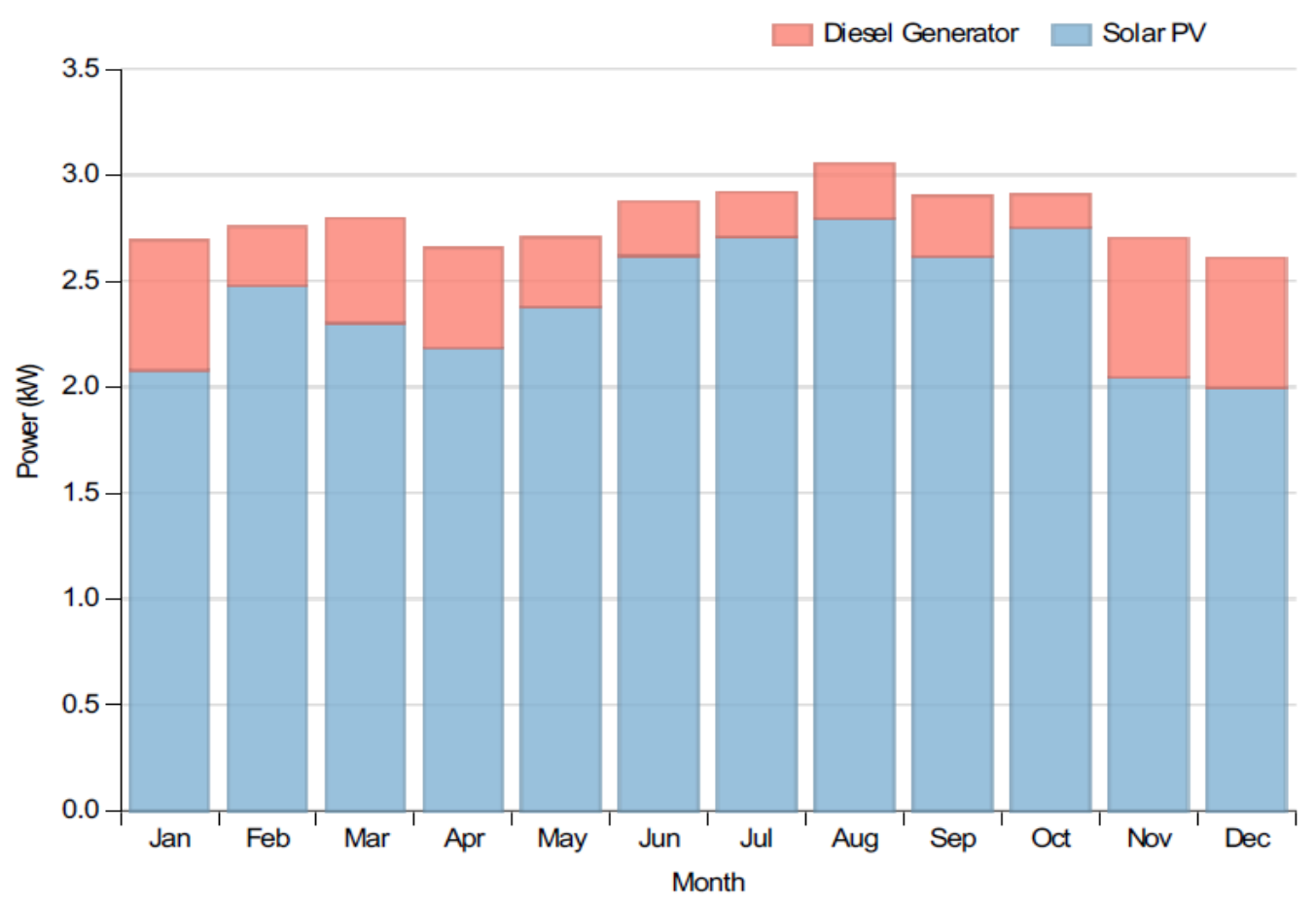

Fig. 10. Monthly average Electrical production from different components in S2 Configuration 


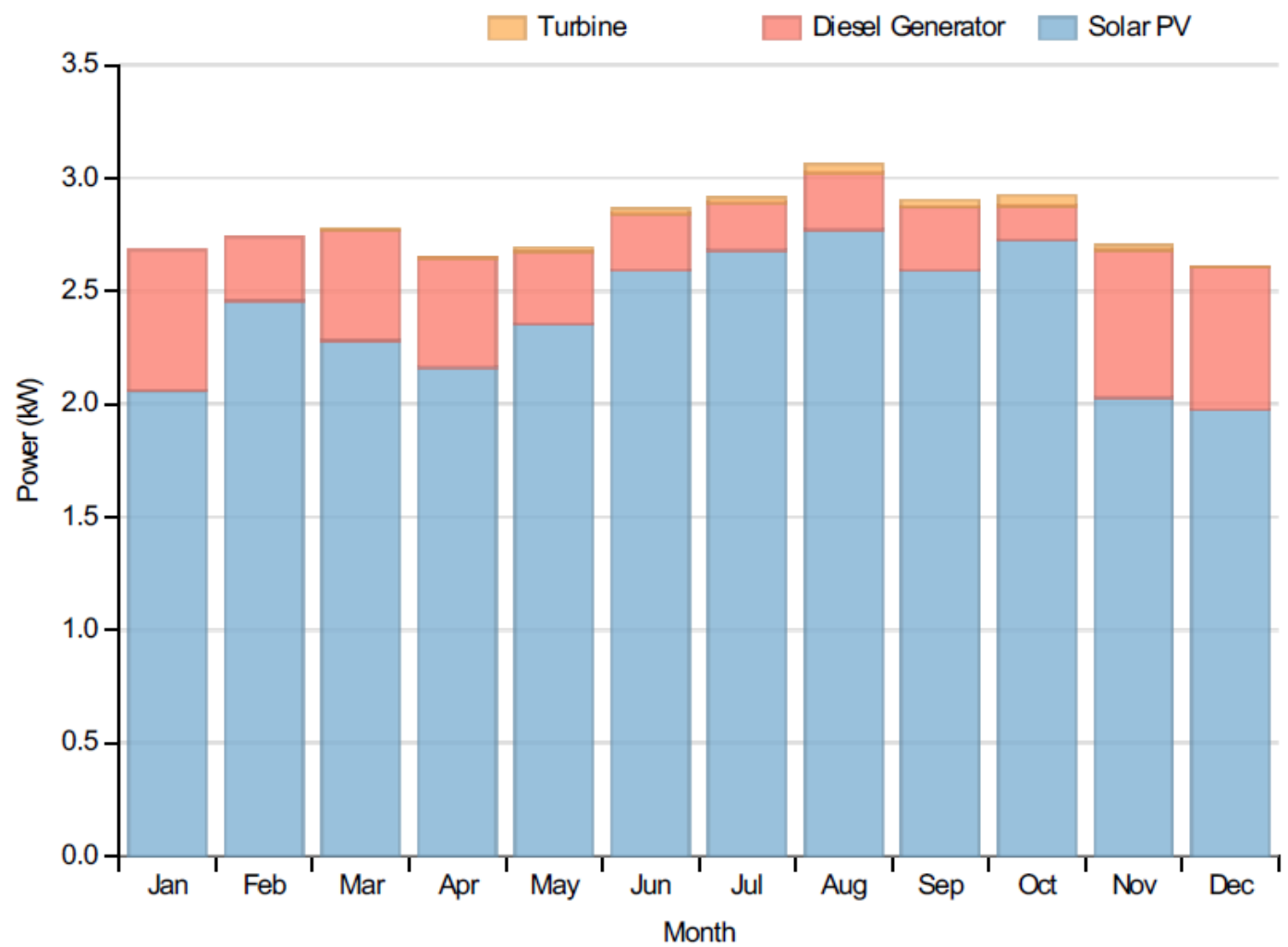

Fig.11. Monthly average Electrical production from different component in S3 Configuration

It can be observed that for S2 and S3 configuration, the renewable energy produces more power to feed the load. The main power production is from the solar-PV, it produces more than $80 \%$ of the total energy produced by the systems. The area sites indicate that the wind energy contributions is not significant as compared with the solar energy, for example, the S3 wind contributes only $0.6 \%$ of the total production while about $14 \%$ is from diesel generators. More power is produced during the day time as shown by DMap in Fig. 12 for S3 configurations. It is evident from the graph that the contribution of the wind energy is insignificant compared to other sources in the system. The Solar-PV and diesel generator can produce enough energy to meet the load demand. During the day the solar-PV produce excess energy which is stored in the battery bank.

Generating electrical power from solar-PV leads to the reduction of diesel generator running time. With traditional power system, the diesel generator runs for a whole year (about 8760 hours), but with HPS, the diesel generator reduces the running time to about 3780 hours per year. This has a significant impact to the amount of fuel burnt/used, and GHG emissions. Henceforth the generator life span increases.

Fig. 13 gives further observations on the load demand of the S3 system in the month of October. It is shown that S3 can meet consumer load and produce some excess energy which can be stored in the storage devices and being used during peak times. It can be seen that solar-PV alone can almost supply all of the load demand during the day. The diesel generator and turbine were used to subsidize the remaining load demand especially during the night time.

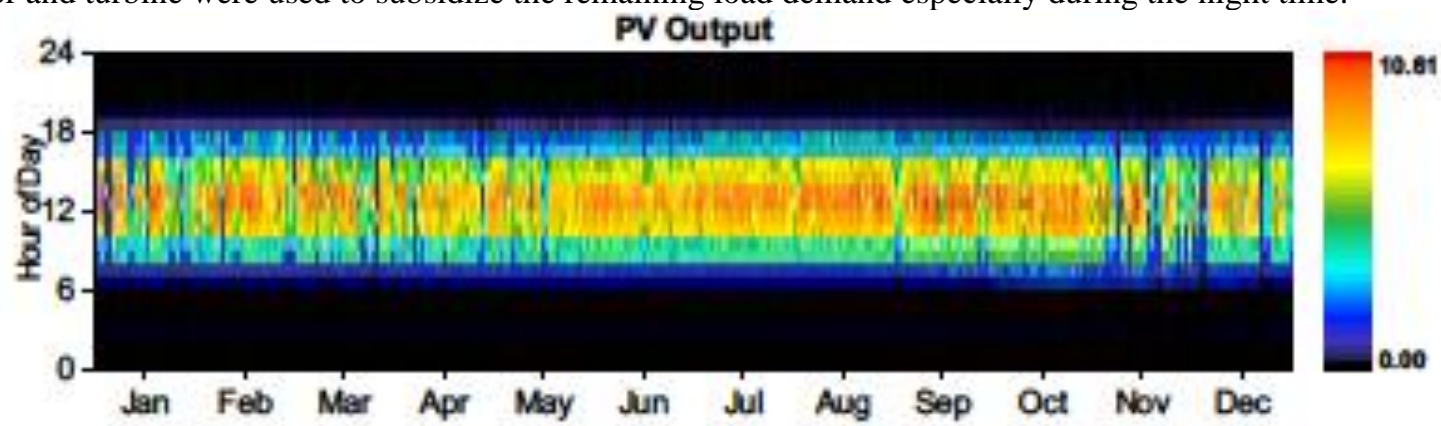

Fig. 12. DMap for Solar-PV power output in S3 architecture 


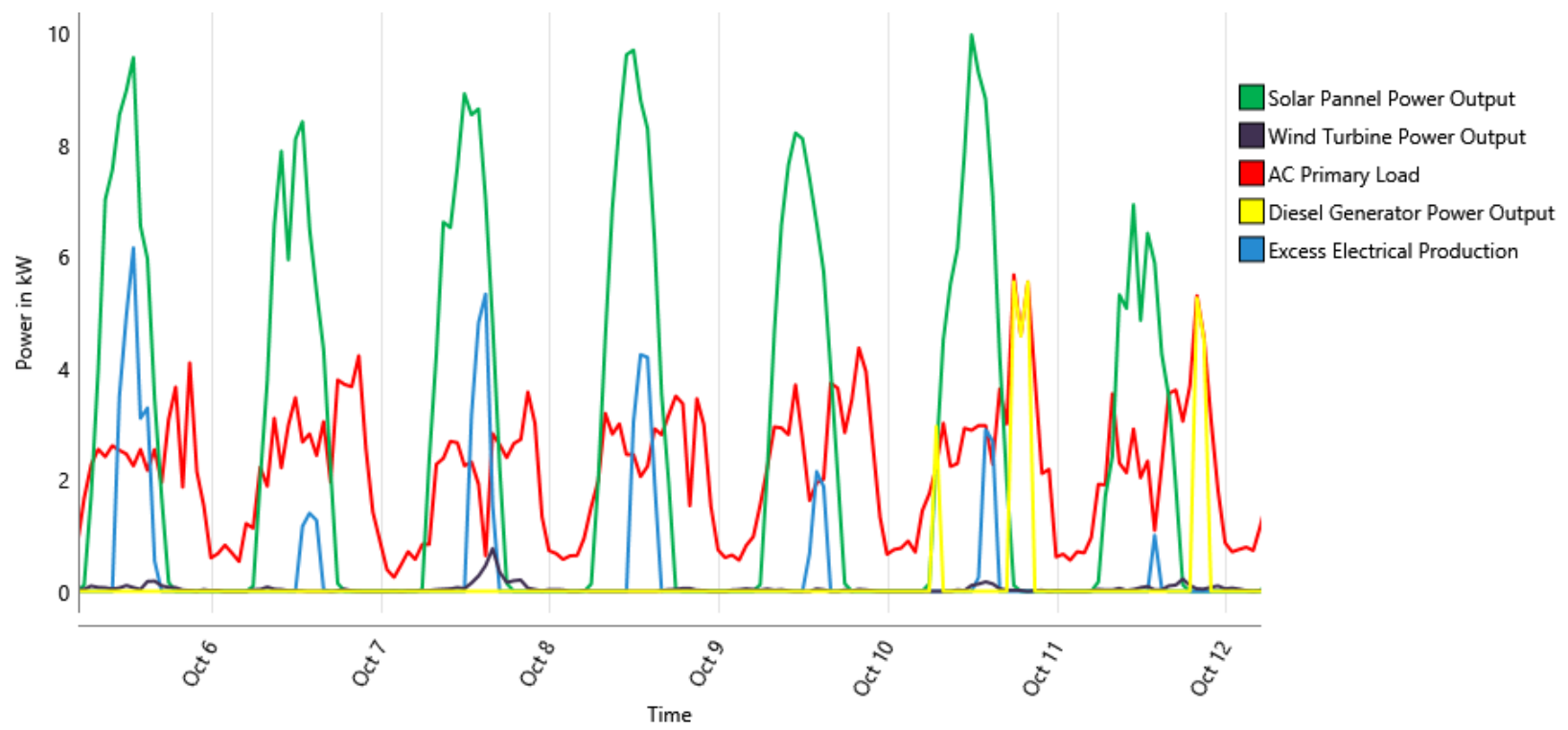

Fig .13. Electrical generation, load demand, power output, and excess energy

\section{CONCLUSION}

This survey-based study has investigated the challenges the MNOs face when using the RE to power up their infrastructures. Correspondingly, the study has evaluated and presented the techno-economic potentials for various power system configurations to power the remotely base stations in Tanzania. The main challenges are high installation cost, unpredictable weather conditions, unavailability of renewable energy facilities, and lack of skilled personnel. In spite of identified challenges, the techno-economic analysis has shown the potential of the renewable energy in powering the remotely cellular network infrastructures in Tanzania. Different configurations for the HPS were analysed in HOMER and simulation results were provided. The results obtained from the cost analysis revealed that the use of HPS can reduce NPC, COE, GHG emissions and increase the renewable energy penetration. The study has also revealed that the S2 system is financially viable, environmental friendly and provides a sustainable solution for powering MNOs' site(s) in Tanzania.

Nevertheless, it was observed that the contribution of wind power was insignificant as the amount of power it contributes is only $0.6 \%$ and increases the capital cost of the system. Therefore, the combination of solar-PV, Diesel generator and Battery, gives an optimized hybrid power system for the studied area. Even though the capital cost is high, the operation cost is low and reduced the NPC and COE. Further, the GHG emissions are significantly reduced. As it can be observed, with conventional diesel generators, the carbon dioxide production is $27,227 \mathrm{Kg} / \mathrm{year}$ but with the HPS it is reduced to about $3,123 \mathrm{Kg} /$ year, accounting for an annual reduction of about $88 \%$. Although the HPSs have higher initial cost, the NPC is lower and they provide a cheap energy and long lifetime. The study findings are useful to the researchers, government, policy maker, power utilities, and environmental agents and may provide useful data for investigating the role that the renewable energy can achieve in supplying electrical energy to the off-grid rural or remote communities in Tanzania.

\section{REFERENCES}

[1] Y. B. Choi, J. Lee, S. Yoo and Y. K. Yoo, "Value Relevance of Customer Equity Beyond Financial Statements: Evidence From Mobile Telecom Industry," Asia-Pacific Journal of Accounting \& Economics, vol. 26, no. 3, pp. 281-300, 2019.

[2] I. Philbeck, "Connecting the Unconnected Working together to achieve Connect 2020 Agenda Targets: A background paper to the special session of the Broadband Commission and the World Economic Forum," ITU, Davos , 2017.

[3] O. M. Babatunde, I. H. Denwigwe, D. E. Babatunde, A. O. Ayeni, T. B. Adedoja and O. S. Adedoja, "Techno-economic assessment of photovoltaic-diesel generator-battery energy system for base transceiver stations loads in Nigeria," Cogent Engineering, 2019.

[4] V. Mancuso and S. Alouf, "Reducing costs and pollution in cellular networks," IEEE Communications Magazine, vol. 49, no. 8, pp. 63-71, 2011.

[5] AHK, "Target Market Study Tanzania: Solar PV \& Wind Power," German Energy Desk, Nairobi, 2013.

[6] T. S. Costa and M. G. Villalva, "Technical Evaluation of a PV-Diesel Hybrid System with Energy Storage: Case Study in the Tapajós Arapiuns Extractive Reserve, Amazon, Brazil," Energy, 2020.

[7] J. Lorincz and I. Bule, "Renewable Energy Sources for Power Supply of Base Station Sites," International Journal of Business Data Communications and Networking (IJBDCN), vol. 9, no. 3, pp. 53-74, 2013.

[8] REA, "Energy Access and Use Situation Survey II in Tanzania Mainland 2019/20," National Bureau of Statistics and REA, 2020.

[9] AfDB, "Renewable Energy in Africa: TANZANIA Country Profile," African Development Bank Group, Côte d'Ivoire, 2015. 


\title{
International Journal of Advanced Research in Computer and Communication Engineering
}

\author{
Vol. 10, Issue 4, April 2021
}

\section{DOI 10.17148/IJARCCE.2021.10408}

[10] S. Mastorakis and G. A. Vokas, "Feasibility study of different powering supply schemes for rural applications," in 4th European Conference PV-Hybrid and Mini-Grid 2008 - OTTI, Vouliagmeni Athens, 2008.

[11] GSMA, "The Green Power for Mobile Programme Bi Annual report," GSMA in Partner with Netherlands, London, 2014.

[12] TanzaniaInvest, "Tanzania Telecoms Sector Report," $26 \quad$ September $2016 . \quad$ [Online]. Available: http://www.tanzaniainvest.com/telecoms/tanzania-telecoms-sector-report. [Accessed 28 December 2020].

[13] S. Avikal, R. Singhal, R. Sajwan, R. K. Tiwari and R. Singh, "Selection of Best Power Supply Source for Telecom Towers in Remote Areas," International Journal of Mathematical, Engineering and Management Sciences, vol. 5, no. 5, pp. 913-925, 2020.

[14] TowerXchange, "Demand Forecasts for Telecom Infrastructure Equipment and Services in Sub-Saharan Africa," Towerxchange, 17 September 2020. [Online]. Available: https://www.towerxchange.com/wp-content/uploads/2020/09/TX_AfricaDemandForecast_2020.pdf. [Accessed 21 January 2021].

[15] M. Hankins, A. Saini and P. Kirai, "Target Market Analysis: Tanzania’s Solar Energy Market," German Federal Ministry Of Economics and Technology (BMWi), Berlin, 2009.

[16] I. P. D. Silva, "AFRICA Policy Review," 18 August 2016. [Online]. Available: http://africapolicyreview.com/analysis/four-barriers-diffusionsolar-energy-technologies-africa-trends-kenya/. [Accessed 4 August 2020].

[17] A. A. Barakabitze, E. J. Kitindi, C. Sanga , A. Shabani , J. P. Masamaki and G. Kibirige, "New technologies for disseminating and communicating agriculture knowledge and information (AKI): Challenges for Agricultural Research Institutes (ARI) in Tanzania," Electronic Journal of Information Systems in Developing Countries, vol. 70, pp. 1-22, 2015.

[18] D. Marquet, M. Aubrée, S. Le Masson, A. Ringnet, P. Mesguich and M. Kirtz, "The first thousand optimized solar BTS stations of Orange group," in Telecommunications Energy Conference (INTELEC), IEEE 33rd International, 2011.

[19] S. A. Chowdhury and S. Aziz, "Solar-diesel hybrid energy model for Base Transceiver Station (BTS) of mobile phone operators," in IEEE 2nd International Conference on the Developments in Renewable Energy Technology (ICDRET 2012), 2012.

[20] L. J. Olatomiwa, S. Mekhilef and A. S. Huda, "Optimal Sizing of Hybrid Energy System for a Remote Telecom Tower: A case study in Nigeria," in IEEE Conference on Energy Conversion (CENCON), Johor Bahru, 2014.

[21] J. S. Goud and R. Kalpana, "Optimal sizing of hybrid power supply system for telecommunication BTS load to ensure reliable power at lower cost," in International Conference on Technological Advancements in Power and Energy ( TAP Energy), Kollam, India, 2017.

[22] V. Mahajan, R. Mahajan and R. Misra, "Indian Telecom Industry: Challenges and Use of Analytics to Manage Customer Churn," in Handbook of Research on Expanding Business Opportunities With Information Systems and Analytics, IGI Global Publishers, 2019, pp. 353-376.

[23] P. Nema , R. K. Nema and S. Rangnekar, "PV-solar / wind hybrid energy system for GSM/CDMA type mobile telephony base station," International Journal of Energy and Environment, vol. 1, no. 2, pp. 359-366, 2010.

[24] S. Yilmaz and F. Dincer, "Optimal design of hybrid PV-Diesel-Battery systems for isolated lands: A case study for Kilis, Turkey," ELSEVIER Renewable and Sustainable Energy Reviews, vol. 77, p. 344-352, 2017.

[25] Y. Devrim and L. Bilir, "Performance investigation of a wind turbine-solar photovoltaic panels-fuel cell hybrid system installed at İncek region - Ankara, Turkey," ELSERVIER Energy Conversion and Management, vol. 126, p. 759-766, 2016.

[26] J. Dekker, M. Nthontho and S. Chowdhury, "Economic analysis of PV/diesel hybrid power systems in different climatic zones of South Africa," ELSEVIER International Journal of Electrical Power \& Energy Systems, vol. 40, no. 1, p. 104-112, 2012.

[27] R. Sebastian, "Modelling and simulation of a high penetration wind diesel system with battery energy storage," ELSEVIER International Journal of Electrical Power \& Energy Systems, vol. 33, no. 3, p. 767-774, 2011.

[28] W. M. Amutha and V. Rajini, "Cost benefit and technical analysis of rural electrification alternatives in southern India using HOMER," Renewable and Sustainable Energy Reviews, vol. 62, pp. 236-246, 2016.

[29] OECD/IEA, "Technology Roadmap: Solar Photovoltaic Energy," INTERNATIONAL ENERGY AGENCY, Paris, 2014.

[30] D. Feldman, G. Barbose, M. Robert, T. James, S. Weaver, N. Darghouth, R. Fu, C. Davidson, S. Booth and R. Wiser, "Photovoltaic System Pricing Trends: Historical, Recent, and Near-Term Projections," US Department of Energy, 2014.

[31] E. M. Nfah, J. M. Ngundam and R. Tchinda, "Modelling of solar/diesel/battery hybrid power systems for far-north Cameroon," ELSEVIER Renewable Energy, vol. 32, no. 5, p. 832-844, 2007.

[32] S. M. Shaahid and I. El-Amin, "Techno-economic evaluation of off-grid hybrid photovoltaic-diesel-battery power systems for rural electrification in Saudi Arabia-A way forward for sustainable development," ELSEVIER Renewable and Sustainable Energy Reviews, vol. 13, no. 3, p. 625-633, 2009.

[33] D. Saheb-Koussa, M. Haddadi and M. Belhamel, "Economic and technical study of a hybrid system (wind-photovoltaic-diesel) for rural electrification in Algeria," ELSEVIER Applied Energy, vol. 86, no. 7-8, p. 1024-1030, 2009.

[34] S. Rehman , M. Alam, J. P. Meyer and L. M. Al-Hadhrami, "Feasibility study of a wind-pv-diesel hybrid power system for a village," ELSEVIER Renewable Energy, vol. 38, no. 1, p. 258-268, 2012.

[35] M. K. Shahzad, A. Zahid, T. u. Rashid, M. A. Rehan, M. Ali and M. Ahmad, "Techno-economic feasibility analysis of a solar-biomass off grid system for the electrification of remote rural areas in Pakistan using HOMER software," Renewable Energy, vol. 106 , pp. 264-273, 2017.

[36] NCEP, "Global Weather Data for SWAT," The National Centers for Environmental Prediction, 2014. [Online]. Available: https://globalweather.tamu.edu/. [Accessed 25 June 2020].

[37] HOMER Energy, HOMER Pro V3.7 User Manual, 2016. 